\section{Does the patient know best?}

EDIToR,-Jonathan S Nguyen-Van-Tam and Daryll M Baker conclude that patients (rather than their general practitioners) know best when they refer themselves to casualty having already been seen by their general practitioners.' Their evidence is based on the fact that 12 of 36 such patients were then admitted to hospital. They assume, however, that every patient who was admitted required admission-in other words, that the hospital rather than the general practitioner always knew best. No objective evidence for this assertion is given, such as operation rates for surgical patients. On the data provided it is equally possible that the patients were able to "wind up" the hospital doctor and gain admission because the hospital doctor was less experienced, less wise to the patient's manipulations, and knew the patient less well than the general practitioner.

If general practitioners are failing to refer genuine patients it is important that hospitals tell them both from the point of view of persona audit and to provide a district audit of general practitioners' care. Conversely, purchasers will need to observe the number of patients, and the nature of their complaints, inappropriately referred by general practitioners as emergencies as there is now a financial incentive for fundholding practices to do this. It is also a good time to review practices that provide their own casualty type services as hitherto such practices have received no remuneration and have had to pay for dressings themselves.

MICHAEL DIXON

\section{College Surgery,}

Cullompton,

Devon EX15 1TG

1 Nguyen-Van-Tam JS, Baker DM. General practice and acciden and emergency department care: does the patient know best? BMF 1992;305:157-8. (18 July.)

EDITOR, - The paper by J S Nguyen-Van-Tam and D M Baker seems to have serious deficiencies. ${ }^{\prime}$ The authors incorrectly cite the work of Davison et al in stating that this showed that $8 \%$ of those attending an accident and emergency department had already consulted their general practitioner with the same problem. ${ }^{2}$ Davison et al studied 587 patients attending an accident and emergency department; 78 had been referred by their general practitioner and a further 47 (classified as being "neither accidents nor emergencies") had previously seen their general practitioner with the presenting complaint. At the very least $125(21 \%)$ patients had consulted their general practitioner. The previous treatment for the 283 patients classified as being self referred accidents and emergencies was not reported.

Nguyen-Van-Tam and Baker state that patients attending accident and emergency departments for another opinion often encounter scepticism from staff. This does not conform with our experience, and we would be interested to learn of research evidence supporting this assertion.

The authors describe sampling every tenth case from 4560 consecutive patients attending an accident and emergency department. Only 16 of the potential sample of 456 patients seem to have been in exclusion categories (patients not registered with a local practice, unconscious patients, patients presenting after self poisoning or road accidents, and those certified dead on arrival). This is a

\section{Advice to authors}

Priority will be given to letters that are less than 400 words long and are typed with double spacing. All authors should sign the letter. Please enclose a stamped addressed envelope for acknowledgment.

remarkably small proportion and casts doubt on the representativeness of the sample. Davison et al, for example, found that non-registration alone accounted for $12 \%$ of their attenders. ${ }^{2}$

The authors state that valid responses were obtained from $84 \%$ of those sampled. Probably disproportionate number of the seriously ill, and especially those in need of immediate care, were non-responders. Non-responders may therefore have been the group most likely to require admission. The outcome of their consultations should have been reported.

The authors assert that patients who refer themselves to accident and emergency departments having already seen a general practitioner do so "despite having seen a general practitioner who clearly had not recommended such a course of action." But they do not report either the interval between the previous consultation and attendance at the accident and emergency department or the action that general practitioners had advised the patients to take should deterioration occur. Their supposition lacks support.

Finally, they comment that an "overlap of care due to self referral occurred in almost $10 \%$ of cases." It would be helpful to know how the authors defined overlap as the extrapolation to total workload does not seem justified.

J DALE

Accident and Emergency Department, E GLUCKSMAN

King's College Hospital,

London SE5 9RS

1 Nguyen-Van-Tam JS, Baker DM. General practice and accident and emergency department care: does the patient know best? $B M \mathcal{F}$ 1992;305:157-8. (18 July.)

2 Davison AG, Hildrey ACC, Floyer MA. Use and misuse of an accident and emergency department in the east end of London. I R Soc Med 1983;76:37-40.

EDIToR,-I do not believe that admission to hospital from an accident and emergency department can be taken as the sole criterion of the need for admission.' Many admissions are a consequence of lack of knowledge of patients' history both medical and social, and the relative inexperience of junior accident and emergency staff. I suggest that the outcome of admission and disposa thereafter would be more valid measures of the need of attendance. For example, how many patients are discharged within 24 hours?

Glasgow G76 7BX

MALCOLM PICKARD

1 Nguyen-Van-Tam JS, Baker DM. General practice and accident and emergency department care: does the patient know best? BMf 1992;305:157-8. (18 July.)

EDIToR,-Jonathan S Nguyen-Van-Tam and Daryll M Baker's conclusions are flawed without an analysis of the reason for the patients' admis- sion. ${ }^{1}$ It is not uncommon for patients who have seen their general practitioner to refer themselves to an accident and emergency department for a second opinion, particularly for children suffering from febrile diseases who can well be managed at home and are in no danger from their disease. The casualty officer is then left in the unenviable position of lacking the general practitioner's experience and ability to follow up the treatment of the disease and lacking knowledge of the patient's home circumstances. The casualty officer sees this patient just once and therefore tends to play safe. In consequence, several unnecessary admissions are made to the hospital's expensive and overbusy wards. The fact that a patient is admitted from casualty does not justify a conclusion that he or she is seriously ill.

Thornhills Medical Group,

R M RIDSDILL SMITH

Larkfield,
Kent ME20 6BQ

I Nguyeu-Van-Tam JS, Baker DM. General practice and accident and emergency department care: does the patient know best? BMF 1992;305:157-8. (18 July.)

EDITOR,-Jonathan S Nguyen-Van-Tam and Daryll M Baker's study does not address severa important points. ${ }^{1}$ There is no mention of the time between the patients seeing their general practitioner and presenting to the accident and emergency department. If the patients had seen their general practitioner about an ingrowing toenail there may have been several days, even weeks, between the two consultations. Congestive heart failure, asthma, and ischaemic heart disease may be stable one day and the next be severe enough to warrant admission. To ask simply, "Have you seen your general practitioner previously about this problem?" is to include almost all chronic conditions dealt with by general practitioners.

No mention is made of why the patients attended the accident and emergency department instead of returning to their general practitioner. Weekends are often seen as a time when the surgery is closed, so the accident and emergency department is then the next most available source of medical aid. Long times to the next available appointment - often two or three days - may also make the "instant" consultation at the accident and emergency department seem more attractive. The 24 hour nature of the accident and emergency department may also tempt travelling representatives, business people, or those who miss a consultation with their general practitioner to seek a guaranteed consultation outside the normal surgery hours, usually 9 am to $6 \mathrm{pm}$.

The study grouped together those who were referred to the accident and emergency department by their general practitioners for good clinical reasons and those who referred themselves; $28 \%$ of the authors' selected group had been seen by a general practitioner. General practitioners often send people to an accident and emergency department for rapid radiography of possible fractures, if they have lacerations (particularly those involving glass), for treatment of burns, and for various other problems best dealt with in such departments; yet the study portrays this as almost a failing of the general practitioners.

In fact, only 36 people of the total of 371 -less than $10 \%$ - had gone to the accident and emergency department of their own accord after seeing 